\title{
Airborne Bacterial Interactions: Functions Out of Thin Air?
}

\author{
Bianca Audrain, Sylvie Létoffé and Jean-Marc Ghigo* \\ Genetics of Biofilms Laboratory, Department of Microbiology, Institut Pasteur, Paris, France
}

Bacteria produce and release a large diversity of small molecules including organic and inorganic volatile compounds, hereafter referred to as bacterial volatile compounds (BVCs). Whereas BVCs were often only considered as wasted metabolic by-product sometimes perceived by animal olfactory systems, it is increasingly clear that they can also mediate cross-kingdom interactions with fungi, plants and animals. Recently, in vitro studies also reported the impact of BVCs on bacterial biology through modulation of antibiotic resistance, biofilm formation and virulence. Here, we review BVCs influence on bacterial adaptation to their environment and discuss the biological relevance of recently reported inter- and intra-species bacterial interactions mediated by BVCs.

Keywords: bacterial volatile compounds, metabolism, signaling, bacterial interactions, biofilm, antibiotic resistance

\section{OPEN ACCESS}

Edited by:

Paolina Garbeva

Netherlands Institute of Ecology,

Netherlands

Reviewed by:

Antoine Danchin,

AMAbiotics SAS, France

Richard Splivallo,

University of Frankfurt, Germany

*Correspondence:

Jean-Marc Ghigo

jmghigo@pasteur.fr

Specialty section:

This article was submitted to

Plant Biotic Interactions,

a section of the journal

Frontiers in Microbiology

Received: 01 September 2015 Accepted: 08 December 2015 Published: 22 December 2015

Citation:

Audrain B, Létoffé S and Ghigo J-M (2015) Airborne Bacterial Interactions:

Functions Out of Thin Air?

Front. Microbiol. 6:1476.

doi: 10.3389/fmicb.2015.01476

\section{INTRODUCTION}

While the contribution of diffusible soluble secondary metabolites in bacterial ability to communicate, compete or cooperate with neighboring microorganisms has been actively investigated, bacteria also produce and release a wide diversity of volatile compounds that can be readily detected in the bacterial headspace (Schulz and Dickschat, 2007). Nevertheless, the potential biological role(s) of organic and inorganic bacterial volatile compounds or gases (BVCs) was often overlooked. Recent studies, however, demonstrated that they could mediate a variety of interactions between bacteria and their environment. Indeed, several BVCs were shown to influence growth and differentiation in fungi, to induce systemic resistance against bacterial pathogens in plants or to affect behaviors in invertebrates (Figure 1; Gallagher and Manoil, 2001; Ryu et al., 2003; Kai et al., 2008, 2009; Niu et al., 2010; Effmert et al., 2012). In addition of their action on a wide range of eukaryotic organisms, several reports also revealed the potential impact of BVCs on bacteria themselves (Audrain et al., 2015). This review will present the current knowledge on BVCs influence on inter- and intra-species bacterial interactions and will discuss their biological relevance and the interest to further study this particular class of bacterial metabolites.

\section{ROLE OF BVCS IN BACTERIAL COMPETITION}

Bacteria often compete for space, nutrients or others resources through production of metabolic by-products providing them with an advantage over surrounding bacteria. Several BVCs display a direct negative effect, as it is the case for some volatile compounds emitted from rhizosphere bacteria Bacillus, Pseudomonas, Serratia, or Streptomyces affecting bacterial growth. For instance, dimethyl disulfide emitted from Pseudomonas fluorescens and Serratia plymuthica displays bacteriostatic effects against two plant bacterial pathogens, Agrobacterium tumefaciens and A. vitis 


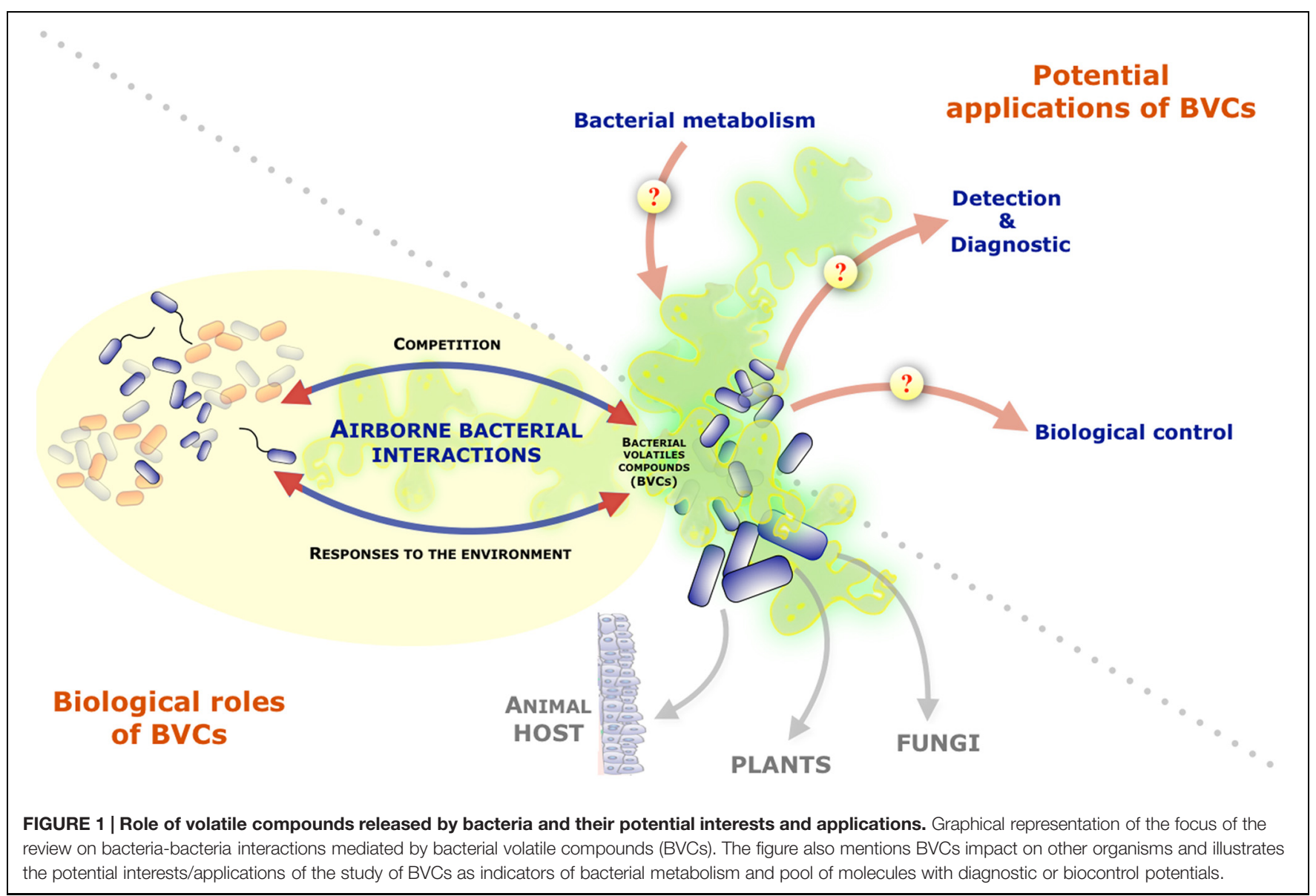

(Dandurishvili et al., 2011). Moreover, albaflavenone produced by Streptomyces sp. exhibits antibacterial activity against Bacillus subtilis (Gurtler et al., 1994).

Some soluble short-chain fatty acids (acetate, succinate, propionate, or isobutyrate) are also able to inhibit growth of several enteropathogens (Salmonella enteritidis, S. typhimurium and Escherichia coli) (Hinton, 1995), and also growth and sporulation of Clostridium perfringens (Wrigley, 2004). Although these experiments were performed using short-chain fatty acids in solution, these metabolites are produced by Veillonella species or Bacteroides fragilis (Hinton, 1995) and several other members of the intestinal microbiota (Effmert et al., 2012) suggesting that volatile short-chain fatty acids could also play a role in control of competing commensals and also enteropathogens in the intestinal tract.

Some BVCs are also able to modulate at a distance the production of antimicrobials. Indeed, volatile compounds produced by Collimonas pratensis increased production of secondary metabolites in P. fluorescens that showed antimicrobial activity against Bacillus sp (Garbeva et al., 2014). In P. aeruginosa, the production of molecules with antimicrobial activity such as pyocyanin seems also to be influenced by volatile compounds (Venkataraman et al., 2011, 2014). A recent study reported that 2,3-butanediol, produced by co-habitant fermenter bacteria such as $S$. marcescens enhances production of $P$. aeruginosa pyocyanin exhibiting antimicrobial activity, which then could help $P$. aeruginosa to occupy a niche, especially in cystic fibrosis lungs (Venkataraman et al., 2014); 2,3-Butanediol and its volatile precursor 2,3-butanedione have thus been detected in airways of cystic fibrosis patients (Whiteson et al., 2014). All these study therefore suggest a potential direct and indirect role of BVCs in bacterial competition.

\section{VOLATILE-DEPENDENT BACTERIAL RESPONSES TO THE ENVIRONMENT}

Several studies described BVCs as potential airborne chemical cues modulating gene expression, membrane permeability or enzyme activation resulting in alteration of bacterial behaviors. For instance, $P$. fluorescens transcriptional response differs upon exposure to volatiles emitted by rhizospheric bacteria such as $C$. pratensis and S. plymuthica, including dimethyl disulfide and benzonitrile, which stimulate the growth of P. fluorescens (Garbeva et al., 2014). BVCs can therefore provide positive information about surrounding microorganisms or environment. Alternatively, aerial exposure to glyoxylic acid and 2,3-butanedione, both produced by $B$. subtilis reduces Burkholderia glumae, P. aeruginosa, Paenibacillus polymyxa and E. coli surface motility (Kim et al., 2013). In the 
case of E. coli, this reduced motility correlates with the downregulation of 30 genes involved in chemotaxy and motility in E. coli (Kim et al., 2013). Several other BVCs such as 1butanol, indole, 2-butanone or acetoin were also shown to influence $E$. coli and $P$. aeruginosa motility (Letoffe et al., 2014).

Bacterial volatile compounds cues also contribute to the development of bacterial community by influencing biofilm formation of Gram-negative and Gram-positive bacteria. Although still mechanistically unclear, volatile compounds such as indole, 1-butanol, 2-butanone, acetoin, ammonia, ethanol, hexadecane, glyoxylic acid, and trimethylamine display positive or negative influence on biofilm formation in one or several tested bacterial species (B. subtilis, E. coli, P. aeruginosa, and Staphylococcus aureus) (Letoffe et al., 2014). Recent studies also demonstrated that volatile acetic acid, a short-chain fatty acid, or ammonia can stimulate biofilm formation in B. subtilis and S. aureus (Nijland and Burgess, 2010; Letoffe et al., 2014; Chen et al., 2015). Whereas exposure to nitric oxide (NO) can positively affects biofilm formation of Shewanella oneidensis, Azospirillum brasilense or Vibrio harveyi (Henares et al., 2013; Barraud et al., 2014), it triggers biofilm dispersion in several Gram-negative and positive bacteria including $P$. aeruginosa, E. coli, V. cholerae, B. licheniformis, S. marcescens, Fusobacterium nucleatum (Barraud et al., 2009b), S. woodyi (Liu et al., 2012), S. enterica (Marvasi et al., 2014), and Neisseria gonorrhoeae (Potter et al., 2009). In P. aeruginosa, the dispersing role of NO could be correlated to degradation of cyclic-di-GMP, a bacterial small molecule playing a central role in the switch between biofilm and planktonic lifestyle (Barraud et al., 2009a; Liu et al., 2012).

The development of high cell density bacterial communities can also lead to the accumulation of organic and inorganic BVCs altering bacterial environment and triggering response to different stresses, including exposure to antibiotics (Heal and Parsons, 2002). For instance, ammonia emitted by bacterial population increases at a distance resistance to tetracycline and ampicillin, and decreases resistance to aminoglycosides in all tested Gram-negative and Gram-positive bacteria exposed to ammonia (Bernier et al., 2011). In E. coli, ammonia mode of action involved its import through the AmtB channel followed by an increase in polyamine synthesis leading to modulation of antibiotic resistance profiles (Bernier et al., 2011). Interestingly, at a distance alkalinization of bacterial growth medium (up to $\mathrm{pH}$ 8.5) upon exposure to volatile ammonia was reported and involved in the increased resistance to ampicillin of S. marcescens and S. rubidaea (Cepl et al., 2014). Similarly, volatile trimethylamine (TMA), produced by reduction of trimethylamine-oxide (TMAO) in TMAO-rich environments such as animal gut and tissues (Barrett and Kwan, 1985; Bos et al., 2013), can also modulate bacterial resistance to several classes of antibiotics through medium alkalinization that affects proton motive force and membrane permeability (Letoffe et al., 2014).

Another inorganic BVC produced by many bacteria, hydrogen sulfide $\left(\mathrm{H}_{2} \mathrm{~S}\right)$, confers multidrug resistance upon different pathogens (B. anthracis, P. aeruginosa, S. aureus, and E. coli) under aerobic conditions via the mitigation of oxidative stress induced by antibiotic treatment upon suppression of DNAdamaging Fenton reaction (Gusarov et al., 2009). Exposure to volatile 2,3-butanedione and glyoxylic acid, both naturally produced by $B$. subtilis GB03, alter E. coli antibiotic resistance profiles, which could be correlated to the upregulation of hipA, encoding an anti-toxin module previously described as mediating persistence (Kim et al., 2013). Alteration of antibiotic resistance by BVCs can also occur at the level of persistence. Indeed, volatile 2-amino-acetophenone (2-AA) enhances antibiotic tolerance by increasing accumulation of persistent bacteria in $P$. aeruginosa and $B$. thailandensis but also in the non-2-AA producer Acinetobacter baumanii (Que et al., 2013), two pathogens isolated during co-infection with $P$. aeruginosa. Since $2-\mathrm{AA}$ promotes persistence by altering bacterial translation, an highly conserved machinery, and it can affect both producing and non-producing bacteria, this suggests that volatile 2-AA could be involved in the ability of Gramnegative bacteria to tolerate antibiotic treatment in polymicrobial infections.

Finally, P. putida exposure to indole produced by E. coli induces an efflux pump leading to an increased antibiotic resistance (Molina-Santiago et al., 2014). However, although it is well established that soluble indole influences drug resistance in several Gram-negative bacteria (Hirakawa et al., 2005; Lee et al., 2008, 2009; Nikaido et al., 2008; Molina-Santiago et al., 2014), its role as a significant airborne signal affecting drug resistance still needs to be confirmed.

\section{CONCLUDING REMARKS}

\section{BVCs, an Untapped Pool of Bioactive Compounds?}

Beyond its fundamental ecological interest, a better understanding of BVC roles, biosynthesis pathways and mechanisms of action could provide new information on the extent of bacterial metabolic potential and lead to clinical or industrial applications (Figure 1). Indeed, several soil-associated bacteria were not only shown to have positive effects on plant resistance but also to control plant diseases by exhibiting antibacterial activity against plant pathogens (Berg, 2009; Pieterse et al., 2014). BVCs can also influence bacterial pathogenesis by altering the production of virulence factors (i.e., 2,3-butanediol increasing virulence factor production in $P$. aeruginosa) or by affecting host cell functions (i.e., colonic homeostasis, $\mathrm{T}$ - and $\mathrm{B}$ cell proliferation responses or cytokine production; KuritaOchiai et al., 1995; Smith et al., 2013; Venkataraman et al., 2014).

Considering bacterial potential for metabolic adaptation to available environmental resources, characterization of the volatile secondary metabolites produced in nature could provide leads for the development of diagnostic tool using BVC as potential biomarker in some pathological situations (Probert et al., 2009). However, most bacteria releasing complex blends of molecules, unraveling the chemical nature and roles of BVCs emitted in 
mixed-species contexts will certainly constitute a major challenge of the field.

\section{Laboratory Conditions vs. Nature: A True Biological Functions for BVCs?}

In the studied described above, experimental set-up using physically separated source of volatile compounds and recipient bacteria unambiguously demonstrated that exposure to BVCs could have important biological functions. While some highly abundant BVCs are likely to play a role in intra- and interbacterial competition and cooperation phenomena, most, if not all studies were performed in laboratory conditions, using artificial media and controlled temperature, atmosphere and BVC concentrations of unknown physiological relevance. Moreover, although BVC-dependent interactions between bacteria (and also plants, fungi, nematodes) are potentially occurring in environments such as soil or mammalian intestines, the high

\section{REFERENCES}

Audrain, B., Farag, M. A., Ryu, C. M., and Ghigo, J. M. (2015). Role of bacterial volatile compounds in bacterial biology. FEMS Microbiol. Rev. 39, 222-233. doi: 10.1093/femsre/fuu013

Barraud, N., Kelso, M. J., Rice, S. A., and Kjelleberg, S. (2014). Nitric oxide: a key mediator of biofilm dispersal with applications in infectious diseases. Curr. Pharm. Des. 21, 31-42. doi: 10.2174/1381612820666140905112822

Barraud, N., Schleheck, D., Klebensberger, J., Webb, J. S., Hassett, D. J., Rice, S. A., et al. (2009a). Nitric oxide signaling in Pseudomonas aeruginosa biofilms mediates phosphodiesterase activity, decreased cyclic di-GMP levels, and enhanced dispersal. J. Bacteriol. 191, 7333-7342. doi: 10.1128/JB.00975-09

Barraud, N., Storey, M. V., Moore, Z. P., Webb, J. S., Rice, S. A., and Kjelleberg, S. (2009b). Nitric oxide-mediated dispersal in single- and multi-species biofilms of clinically and industrially relevant microorganisms. Microb. Biotechnol. 2, 370-378. doi: 10.1111/j.1751-7915.2009.00098.x

Barrett, E. L., and Kwan, H. S. (1985). Bacterial reduction of trimethylamine oxide. Annu. Rev. Microbiol. 39, 131-149. doi: 10.1146/annurev.mi.39.100185.001023

Berg, G. (2009). Plant-microbe interactions promoting plant growth and health: perspectives for controlled use of microorganisms in agriculture. Appl. Microbiol. Biotechnol. 84, 11-18. doi: 10.1007/s00253-009-2092-7

Bernier, S. P., Letoffe, S., Delepierre, M., and Ghigo, J. M. (2011). Biogenic ammonia modifies antibiotic resistance at a distance in physically separated bacteria. Mol. Microbiol. 81, 705-716. doi: 10.1111/j.1365-2958.2011.07724.x

Bos, L. D., Sterk, P. J., and Schultz, M. J. (2013). Volatile metabolites of pathogens: a systematic review. PLoS Pathog. 9:e1003311. doi: 10.1371/journal.ppat.1003311

Cepl, J., Blahuskova, A., Cvrckova, F., and Markos, A. (2014). Ammonia produced by bacterial colonies promotes growth of ampicillin-sensitive Serratia sp. by means of antibiotic inactivation. FEMS Microbiol. Lett. 354, 126-132. doi: 10.1111/1574-6968.12442

Chen, Y., Gozzi, K., Yan, F., and Chai, Y. (2015). Acetic acid acts as a volatile signal to stimulate bacterial biofilm formation. MBio 6, e00392. doi: 10.1128/mBio.00392-15

Dandurishvili, N., Toklikishvili, N., Ovadis, M., Eliashvili, P., Giorgobiani, N., Keshelava, R., et al. (2011). Broad-range antagonistic rhizobacteria Pseudomonas fluorescens and Serratia plymuthica suppress Agrobacterium crown gall tumours on tomato plants. J. Appl. Microbiol. 110, 341-352. doi: 10.1111/j.1365-2672.2010.04891.x

Effmert, U., Kalderas, J., Warnke, R., and Piechulla, B. (2012). Volatile mediated interactions between bacteria and fungi in the soil. J. Chem. Ecol. 38, 665-703. doi: 10.1007/s10886-012-0135-5

Gallagher, L. A., and Manoil, C. (2001). Pseudomonas aeruginosa PAO1 kills Caenorhabditis elegans by cyanide poisoning. J. Bacteriol. 183, 6207-6214. doi: 10.1128/JB.183.21.6207-6214.2001 solubility of BVCs in the liquids present in these environments raises the question of the true aerial nature of BVC-mediated impact on bacteria. Future work will therefore have to clarify the role played by BVCs in bacterial ability to adapt and/or respond to their environments by determining the physiological concentrations of relevant BVCs in diverse environments and to establish, preferentially in vivo, the importance of airborne bacterial interactions in microbial ecology.

\section{ACKNOWLEDGMENTS}

BA, SL, and J-MG are supported by grants from Institut Pasteur, the French government's Investissement d'Avenir Program, Laboratoire d'Excellence "Integrative Biology of Emerging Infectious Diseases" (grant $N^{\circ}$ : ANR-10-LABX-62-IBEID) and by Fondation pour la Recherche Médicale (grant $\mathrm{N}^{\circ}$ : Equipe FRM DEQ20140329508).

Garbeva, P., Hordijk, C., Gerards, S., and de Boer, W. (2014). Volatile-mediated interactions between phylogenetically different soil bacteria. Front. Microbiol. 5:289. doi: 10.3389/fmicb.2014.00289

Gurtler, H., Pedersen, R., Anthoni, U., Christophersen, C., Nielsen, P. H., Wellington, E. M., et al. (1994). Albaflavenone, a sesquiterpene ketone with a zizaene skeleton produced by a streptomycete with a new rope morphology. J. Antibiot. 47, 434-439. doi: 10.7164/antibiotics.47.434

Gusarov, I., Shatalin, K., Starodubtseva, M., and Nudler, E. (2009). Endogenous nitric oxide protects bacteria against a wide spectrum of antibiotics. Science 325, 1380-1384. doi: 10.1126/science.1175439

Heal, R. D., and Parsons, A. T. (2002). Novel intercellular communication system in Escherichia coli that confers antibiotic resistance between physically separated populations. J. Appl. Microbiol. 92, 1116-1122. doi: 10.1046/j.13652672.2002.01647.x

Henares, B. M., Xu, Y., and Boon, E. M. (2013). A nitric oxide-responsive quorum sensing circuit in Vibrio harveyi regulates flagella production and biofilm formation. Int. J. Mol. Sci. 14, 16473-16484. doi: 10.3390/ijms140816473

Hinton, A. Jr. (1995). Hume ME. Antibacterial activity of the metabolic byproducts of a Veillonella species and Bacteroides fragilis. Anaerobe 1, 121-127. doi: 10.1006/anae.1995.1007

Hirakawa, H., Inazumi, Y., Masaki, T., Hirata, T., and Yamaguchi, A. (2005). Indole induces the expression of multidrug exporter genes in Escherichia coli. Mol. Microbiol. 55, 1113-1126. doi: 10.1111/j.1365-2958.2004.04449.x

Kai, M., Haustein, M., Molina, F., Petri, A., Scholz, B., and Piechulla, B. (2009). Bacterial volatiles and their action potential. Appl. Microbiol. Biotechnol. 81, 1001-1012. doi: 10.1007/s00253-008-1760-3

Kai, M., Vespermann, A., and Piechulla, B. (2008). The growth of fungi and Arabidopsis thaliana is influenced by bacterial volatiles. Plant Signal. Behav. 3, 482-484. doi: 10.4161/psb.3.7.5681

Kim, K. S., Lee, S., and Ryu, C. M. (2013). Interspecific bacterial sensing through airborne signals modulates locomotion and drug resistance. Nat. Commun. 4, 1809. doi: $10.1038 /$ ncomms 2789

Kurita-Ochiai, T., Fukushima, K., and Ochiai, K. (1995). Volatile fatty acids, metabolic by-products of periodontopathic bacteria, inhibit lymphocyte proliferation and cytokine production. J. Dent. Res. 74, 1367-1373. doi: 10.1177/00220345950740070801

Lee, J., Attila, C., Cirillo, S. L., Cirillo, J. D., and Wood, T. K. (2009). Indole and 7hydroxyindole diminish Pseudomonas aeruginosa virulence. Microb. Biotechnol. 2, 75-90. doi: 10.1111/j.1751-7915.2008.00061.x

Lee, J., Zhang, X. S., Hegde, M., Bentley, W. E., Jayaraman, A., and Wood, T. K. (2008). Indole cell signaling occurs primarily at low temperatures in Escherichia coli. ISME J. 2, 1007-1023. doi: 10.1038/ismej.2008.54

Letoffe, S., Audrain, B., Bernier, S. P., Delepierre, M., and Ghigo, J. M. (2014). Aerial exposure to the bacterial volatile compound trimethylamine modifies antibiotic 
resistance of physically separated bacteria by raising culture medium $\mathrm{pH}$. MBio 5, e00944-13. doi: 10.1128/mBio.00944-13

Liu, N., Xu, Y., Hossain, S., Huang, N., Coursolle, D., Gralnick, J. A., et al. (2012). Nitric oxide regulation of cyclic di-GMP synthesis and hydrolysis in Shewanella woodyi. Biochemistry 51, 2087-2099. doi: 10.1021/bi201753f

Marvasi, M., Chen, C., Carrazana, M., Durie, I. A., and Teplitski, M. (2014). Systematic analysis of the ability of Nitric Oxide donors to dislodge biofilms formed by Salmonella enterica and Escherichia coli O157:H7. AMB Express 4, 42. doi: 10.1186/s13568-014-0042-y

Molina-Santiago, C., Daddaoua, A., Fillet, S., Duque, E., and Ramos, J. L. (2014). Interspecies signalling: Pseudomonas putida efflux pump TtgGHI is activated by indole to increase antibiotic resistance. Environ. Microbiol. 16, 1267-1281. doi: $10.1111 / 1462-2920.12368$

Nijland, R., and Burgess, J. G. (2010). Bacterial olfaction. Biotechnol. J. 5, 974-977. doi: 10.1002/biot.201000174

Nikaido, E., Yamaguchi, A., and Nishino, K. (2008). AcrAB multidrug efflux pump regulation in Salmonella enterica serovar Typhimurium by RamA in response to environmental signals. J. Biol. Chem. 283, 24245-24253. doi: 10.1074/jbc.M804544200

Niu, Q., Huang, X., Zhang, L., Xu, J., Yang, D., Wei, K., et al. (2010). A Trojan horse mechanism of bacterial pathogenesis against nematodes. Proc. Natl. Acad. Sci. U.S.A. 107, 16631-16636. doi: 10.1073/pnas.1007276107

Pieterse, C. M., Zamioudis, C., Berendsen, R. L., Weller, D. M., Van Wees, S. C., and Bakker, P. A. (2014). Induced systemic resistance by beneficial microbes. Annu. Rev. Phytopathol. 52, 347-375. doi: 10.1146/annurev-phyto-082712-102340

Potter, A. J., Kidd, S. P., Edwards, J. L., Falsetta, M. L., Apicella, M. A., Jennings, M. P., et al. (2009). Thioredoxin reductase is essential for protection of Neisseria gonorrhoeae against killing by nitric oxide and for bacterial growth during interaction with cervical epithelial cells. J. Infect. Dis. 199, 227-235. doi: $10.1086 / 595737$

Probert, C. S., Ahmed, I., Khalid, T., Johnson, E., Smith, S., and Ratcliffe, N. (2009). Volatile organic compounds as diagnostic biomarkers in gastrointestinal and liver diseases. J. Gastrointestin. Liver Dis. 18, 337-343.

Que, Y. A., Hazan, R., Strobel, B., Maura, D., He, J., Kesarwani, M., et al. (2013). A quorum sensing small volatile molecule promotes antibiotic tolerance in bacteria. PLoS ONE 8:e80140. doi: 10.1371/journal.pone.0080140
Ryu, C. M., Farag, M. A., Hu, C. H., Reddy, M. S., Wei, H. X., Pare, P. W., et al. (2003). Bacterial volatiles promote growth in Arabidopsis. Proc. Natl. Acad. Sci. U.S.A. 100, 4927-4932. doi: 10.1073/pnas.0730845100

Schulz, S., and Dickschat, J. S. (2007). Bacterial volatiles: the smell of small organisms. Nat. Prod. Rep. 24, 814-842. doi: 10.1039/b507392h

Smith, P. M., Howitt, M. R., Panikov, N., Michaud, M., Gallini, C. A., Bohlooly, Y. M., et al. (2013). The microbial metabolites, short-chain fatty acids, regulate colonic Treg cell homeostasis. Science 341, 569-573. doi: $10.1126 /$ science. 1241165

Venkataraman, A., Rosenbaum, M. A., Perkins, S. D., Werner, J. J., and Angenent, L. T. (2011). Metabolite-based mutualism between Pseudomonas aeruginosa PA14 and Enterobacter aerogenes enhances current generation in bioelectrochemical systems. Energy Environ. Sci. 4, 4550-4559. doi: 10.1039/C1ee01377g

Venkataraman, A., Rosenbaum, M. A., Werner, J. J., Winans, S. C., and Angenent, L. T. (2014). Metabolite transfer with the fermentation product 2,3-butanediol enhances virulence by Pseudomonas aeruginosa. ISME J. 8, 1210-1220. doi: 10.1038/ismej.2013.232

Whiteson, K. L., Meinardi, S., Lim, Y. W., Schmieder, R., Maughan, H., Quinn, R., et al. (2014). Breath gas metabolites and bacterial metagenomes from cystic fibrosis airways indicate active $\mathrm{pH}$ neutral 2,3-butanedione fermentation. ISME J. 8, 1247-1258. doi: 10.1038/Ismej.2013.229

Wrigley, D. M. (2004). Inhibition of Clostridium perfringens sporulation by Bacteroides fragilis and short-chain fatty acids. Anaerobe 10, 295-300. doi: 10.1016/j.anaerobe.2004.05.006

Conflict of Interest Statement: The authors declare that the research was conducted in the absence of any commercial or financial relationships that could be construed as a potential conflict of interest.

Copyright (C) 2015 Audrain, Létoffé and Ghigo. This is an open-access article distributed under the terms of the Creative Commons Attribution License (CC BY). The use, distribution or reproduction in other forums is permitted, provided the original author(s) or licensor are credited and that the original publication in this journal is cited, in accordance with accepted academic practice. No use, distribution or reproduction is permitted which does not comply with these terms. 